\title{
Seeing Red or Feeling Blue: Differentiated Intergroup Emotions and Ingroup Identification in Soccer Fans
}

\author{
University of Birmingham \\ Matthew J. Farr \\ Loughborough University \\ Rhiannon N. Turner \\ University of Birmingham
}

Richard J. Crisp and Sarah Heuston

\begin{abstract}
In this study we examined how social identity threat, contextualized as soccer fans' reactions to their team's success or failure, can lead to differentiated emotional expression as a function of ingroup identification. We predicted that negative responses to threat (a team losing a match) would be qualitatively differentiated for lower and higher ingroup identifiers in terms of both emotions and action tendencies. English male soccer fans were tested in three sessions (following matches resulting in two losses and one win). The findings supported the hypotheses: following match losses lower identifiers felt sad but not angry, whereas higher identifiers felt angry but not sad. These qualitatively different negative emotional reactions to match loss mediated reported action tendencies. We discuss how these findings support intergroup emotions theory and the predictive utility of social identification in discerning differentiated emotional and behavioral reactions to intergroup threat.
\end{abstract}

KEYWORDS intergroup emotions, social identity

For large numbers of people across the globe, attachment to their soccer club-whether it is the smallest local amateur side or one of the superpower teams with their galáctico playersis something of considerable psychological significance. FIFA, soccer's world governing body, appositely paints a vibrant picture of the game as 'physical movement that simultaneously moves the emotions' (Fédération Internationale de Football Association, n.d.). Truly the world's game, the global popularity of the sport has risen to new heights. Spectator attendances at soccer matches in England are now at their highest for many years (reaching nearly 30 million in the 2003/4 season; by comparison, in $1988 / 9$, this figure was around 18 million).

\footnotetext{
$\overline{\text { Author's note }}$

Address correspondence to R. J. Crisp, School of Psychology, University of Birmingham, Edgbaston, Birmingham B15 2TT, UK [email: r.crisp@bham.ac.uk]
} 
Unfortunately, however, intergroup conflict and social disorder remain an inescapable element of this pastime enjoyed by millions. Within the last decade, research has suggested that violence arises at around $10 \%$ of soccer matches in England (Marsh, Fox, Carnibella, McCann, \& Marsh, 1996). Furthermore, social disorder has not been limited to being a solely domestic concern. The problems posed by 'hooliganism' and widespread social unrest at high-profile international tournaments (particularly within the European Union), such as the 1998 FIFA World Cup in France, and UEFA Euro 2000 in the Netherlands and Belgium, have proved to be of a sufficient magnitude to dominate the headlines, both in Britain and the wider international community.

Fortunately, recent work by social psychologists has demonstrated that the prognosis for the game, and the English national identity abroad, need not be bleak. Greater understanding of the processes which govern intergroup dynamics, as understood through the traditional social identity theory framework (Tajfel \& Turner, 1979), has been making a tangible impact in terms of reducing soccer-related social disorder (see Stott \& Adang, 2004). The contribution of social psychologists to analyses of fan behavior and the policing of matches helped to ensure that the recent UEFA Euro 2004 tournament was the first in recent memory to take place free from significant incidences of soccer-related disorder.

Social identity approaches, and in particular, the elaborated social identity model of crowd behavior (Reicher, 1996) are useful in explaining, and helping to prevent, social disorder which arises as a consequence of intergroup processes (e.g. how opposing fans, and police, react to each other as a function of their ingroup-outgroup category representations). There has been valuable progress made with respect to our understanding of processes of self-categorization, perceptions of (il) legitimacy of actions, and the function of norms (e.g. Stott \& Drury, 2000; Stott \& Reicher, 1998a, 1998b; Stott, Hutchison, \& Drury, 2001). Attention has not, however, been focused on the ways in which particular ingroup-threatening events on the pitch can affect emotions. Such emotions in turn affect the likelihood of specific action tendencies such as confrontation versus avoidance, with confrontation being a potential precursor to social disorder. In this article, using intergroup emotions theory (Mackie, Devos, \& Smith, 2000; Smith, 1993, 1999), we conceptualize soccerrelated social identity processes in terms of differing emotional responses to an ingroup threat (for example, the team's defeat), which may occur in terms of differing levels of commitment (i.e. social identification) to that ingroup.

\section{Social identity and sporting contexts}

The social identity approach (by this we mean social identity theory, Tajfel \& Turner, 1986, and self-categorization theory, Turner, Hogg, Oakes, Reicher, \& Wetherell, 1987) provides a logical and coherent account of the processes which lead individuals to connect themselves to groups, and what this connection-that is, social identification-means for the individuals concerned. In particular, because of a motivational drive toward self- and group-enhancement (e.g. Tajfel \& Turner, 1986, see also Abrams \& Hogg, 1998; Hogg \& Abrams, 1988), we can consider ingroups by their very nature to be of emotional significance to the self-concept. The sporting world provides many sources for strong and enduring social identification. In spectator sport, the personal psychological lives of individuals can be tied to the fates of their chosen teams. Cialdini and colleagues' (1976) classic study of 'basking in reflected glory' demonstrated the simple power of winning and losing upon collective self-esteem, a vivid illustration of the grip that meaningful social memberships can exert over self-perception. In this study more students demonstrated their affiliation with their university after their university team won a football game than after losing a game. Their findings also hinted at the strategy of 'cutting off reflected failure', later elucidated by Snyder, Lassegard, and Ford (1986) and Wann and Branscombe (1990); following group failure 
affiliation is de-emphasized, and members distance themselves from the group. Both strategies appear to be means of managing selfesteem; either by capitalizing on membership of a successful group, or by preventing oneself from being tarnished by affiliation with an unsuccessful group.

This apparent link between sports team affiliation and self-esteem was subsequently confirmed by Hirt, Zillmann, Erickson, and Kennedy (1992). They showed that fans who considered their team allegiance to be an important part of their identity considered their team's success and failure as constituting personal success and failure. In particular, a team's poor performance could markedly lower supporters' self-evaluations and mood. Recent studies have also suggested a link between high levels of identification and mood, as well as a link to aggressive tendencies. Wann, Dolan, McGeorge, and Allison (1994, Study 2) had college students attend their local basketball teams' home games and complete measures of identification and affect. They found that following a loss, high identifiers showed a greater increase in negative mood and a greater decrease in positive mood than low identifiers. Highly identified fans have also been shown to report higher levels of hostile and instrumental aggression (Wann, Carlson, \& Schrader, 1999), and to be more likely to injure some member of a rival team (Wann, Hunter, Ryan, \& Wright, 2001; Wann, Peterson, Cothran, \& Dykes, 1999).

Beyond such generalized self- and groupbased affect, research in the social identity field has not prioritized the decomposition of such affective responses. Whereas feelings toward an outgroup can be summarized as constituting negative affect (put simply, 'bad feeling'), we can actually go further in exploring the specific emotional components which constitute such 'bad feelings'. Such a focus on specific emotions, which provide a qualitatively and experientially richer understanding of intergroup behavior, forms the central pillar of intergroup emotions theory (Mackie et al., 2000; Smith, 1993, 1999). Building upon the basic principles which underlie the social identity approach (i.e. the self as indivisible from the social context), the theory addresses those emotions people experience when they think about or confront members of an outgroup.

\section{Intergroup emotions}

Intergroup emotions theory (Mackie et al., 2000; Smith, 1993, 1999) builds on a combination of two social psychological perspectives; appraisal theories of emotion (Frijda, 1986), which argue that emotions follow from events related to the individual or the personal self, and social identity theory (Tajfel \& Turner, 1979), which posits that when group membership is salient it constitutes an integral part of the self, whereby individuals come to regard themselves as relatively interchangeable with other group members. The theory argues that when group membership is salient, people react emotionally when situations or events affect the ingroup. Smith (1993) argued that specific appraisals made during experience with the outgroup would lead to specific emotions and subsequent action tendencies. If an outgroup was seen as pushy, for example, this might elicit anger, leading to a tendency to aggress against the group, or if an outgroup was seen as dirty, this might elicit disgust and lead to avoidance of that group.

Mackie et al. (2000) investigated the effect of the strength of the ingroup relative to the outgroup on different emotions and action tendencies. Specifically, they proposed that when the ingroup is in a strong position relative to the outgroup, this should elicit anger, leading to offensive action tendencies toward the outgroup. In contrast, when the ingroup is in a weak position relative to the outgroup, this should elicit fear, resulting in avoidance of the outgroup. Across three studies, participants categorized themselves into one of two groups depending on their position on an emotive issue (e.g. punishments for drug use, equal rights for homosexual couples). The degree of support for the point of view of the ingroup relative to the outgroup was then measured (Study 1) or manipulated (Studies 2 and 3). Mackie et al. (2000) 
found when the ingroup position was stronger than the outgroup position, more anger was elicited and there was a greater inclination to oppose or confront the outgroup. Crucially, the effect on approach action tendencies was mediated by anger. There was no evidence that being a member of a weak group led to avoidance action tendencies via fear. There was, however, some limited evidence (Study 3) that being in the weak group led to feelings of contempt, which was associated with the desire to move away from the outgroup.

Silver, Miller, Mackie, \& Smith (2001; cited in Devos, Silver, Mackie, \& Smith, 2002) found greater evidence for the role of being in a weak group position on fear and avoidance action tendencies. Female undergraduates were asked to imagine themselves walking down a local street late at night and being unjustly accused of breaking a car's side mirror. To induce appraisals that might lead to fear, the male owner of the car was described as threatening and aggressive. Silver et al. (2001) found that participants appraised themselves as weak in the situation, more so when they were the sole ingroup member encountering multiple outgroup members. They also showed high levels of fear and a desire to move away from the outgroup. The weaker participants felt, the more fear they experienced and the more they wanted to move away from the antagonist. The effect of an appraisal of weakness on avoidance action tendencies was mediated by participants' reported levels of fear.

In sum, group-based emotions-for example, shared fear, sadness, anger, guilt-arise when a particular intergroup event is weighed up in terms of its implications for the ingroup. One can see how this basic idea makes a lot of sense in all sorts of intergroup contexts. For instance, when the news emerged that three of the perpetrators of the July 7, 2005 terrorist attacks on London came from the English city of Leeds, residents of Leeds were forced to consider the implications of this for their own group memberships (e.g. BBC News Online, 2005). That is, how does this event impact upon the notion of 'us' as citizens of Leeds, English people, Muslims, non-Muslims, and so on? Through considering an ingroupthreatening event, individuals can be thought to experience an affective response which constitutes an emotion directed toward 'them', the outgroup, on the basis of a dichotomized, intergroup frame of reference. Specifically, and of importance for the study we report here, research on intergroup emotions theory supports the notion that in intergroup contexts specific emotions can be experienced that are linked directly to group membership, that qualitatively different emotions will be experienced as a function of context, and that these different emotions will lead to different behavioral (action) tendencies. In the research we report, we tested a novel moderator of experienced emotion that was derived directly from work on social identity theory-perceivers' degree of ingroup identification.

\section{This research}

We argue that as well as existing moderators that lead to qualitatively different intergroup emotions and action tendencies (Mackie et al., 2000; Silver et al., 2001) we can specify a further moderator derived directly from work on social identity theory. We possess multiple social identities, which vary in the degree to which they are salient (or not) at particular times (for a review, see Crisp \& Hewstone, 2006). Put another way, we can identify to a greater or lesser extent with a range of social categories at different times. Ingroup identification can be defined as 'the extent to which group members feel strong ties with their group' (Spears, Doosje, \& Ellemers, 1999 , p. 85). Consistent with the above, it is well established that such ingroup identification is variable (e.g. Branscombe, Wann, Noel, \& Coleman, 1993; Doosje, Ellemers, \& Spears, 1995; for reviews see Brown \& Williams, 1984; Hinkle \& Brown, 1990), and this variability in social identification has strong predictive validity when combined with value or distinctiveness threat. This is the case with respect to a range of intergroup attitudes and behaviors ranging from self-stereotyping (e.g. Spears, Doosje \& Ellemers, 1997), through stereotypic 
differentiation (Doosje et al., 1995), perceived group variability (Ellemers, Spears, \& Doosje, 1997) and intergroup bias (e.g. Branscombe \& Wann, 1994; Jetten, Spears, \& Postmes, 2004; Spears, Jetten, \& Scheepers, 2002).

As we noted earlier, some work has already established ingroup identification as an important predictor of generalized affective reactions in sporting contexts. Wann et al. (1994) found that following a loss, high identifiers showed a greater increase in negative mood and a greater decrease in positive mood than low identifiers. Although these findings only show that identification had an impact on broad negative or positive affect, Wann et al.'s mood questionnaire included both items that referred to anger emotions (e.g. angry) and depressed emotions (e.g. sad). This raises the possibility that had these specific negative emotions been differentiated then a dissociation may have been observed for lower and higher identifiers.

Some further evidence that specific emotions can be elicited as a function of identification comes from Sloan (1989). In this study 46 regular fans of a basketball team (who could be considered committed, high identifiers) recorded their emotions before and after eight home basketball games. Sloan found that anger increased after a loss, but was almost nonexistent after a win. In contrast, happiness decreased after a loss and rose following a win. These findings were also replicated among American football fans. In contrast, fans watching an amateur boxing tournament, where the competitors had only recently volunteered, and therefore where there had been little opportunity for fans to form an attachment (i.e. participants could be regarded as lower identifiers), showed no changes in anger or happiness across the course of the matches. Sloan's study is important in that it indicates that the degree of commitment to a sports team can have an impact on specific emotions (anger and happiness). However, because the two emotions used here are still broadly positive versus negative, we cannot be sure that the results simply reflect differences in generalized affective reaction, rather than being attributable to qualitatively different emotional reactions.
Although not in a sporting context, some studies have also indicated that identification may not only affect emotions, but also associated action tendencies. Recategorization from two subgroups into a merged superordinate group can constitute a threat to identity, especially for highly identifying subgroup members (see Crisp, 2006; Crisp, Stone, \& Hall, 2006). Yzerbyt, Dumont, Wigboldus, and Gordijn (2003) examined emotional reactions and action tendencies in response to recategorization as a function of identification. They asked Frenchspeaking Belgian participants enrolled at the Catholic University of Louvain (UCL) to read a bogus newspaper story about how English was being enforced as the sole language in the third, fourth and fifth years of University. Participants either had their common identity (recategorization) with these students made salient (they were told they were being compared, as students, with professors), or their subgroup membership was made salient (they were told that UCL students were being compared with students at other universities). After reading the newspaper article, participants reported the extent to which they felt anger, sadness, fear and happiness, and reported their action tendencies; whether they intended to exhibit approach behaviors (e.g. intervene, get angry), do nothing, or avoid the situation (e.g. stop thinking about it). Yzerbyt and colleagues found that in the common ingroup condition high identifiers showed significantly more anger and a greater intention to engage in approach behaviors than low identifiers, who were marginally more likely than high identifiers to have a tendency to avoid the situation.

There is therefore indicative evidence that identification has a role to play in predicting emotional reactions to ingroup threat and associated action tendencies. However, although some of the above studies have focused in on specific emotions (e.g. anger), none have shown a dissociation of specific emotions that cannot be attributed to broadly affectively positive or negative reactions. In other words, to be sure that qualitatively different reactions are being experienced in some context it is necessary to show that two similarly valenced, but distinct 
emotions can be experienced, with associated (but again distinct) action tendencies.

Here we extend theorizing in both the social identity and intergroup emotion domains by predicting qualitatively different emotional reactions to intergroup threat and corresponding differentiation in terms of action tendencies. We make our predictions with respect to two negative, but qualitatively different, relevant emotions in the context of sporting team success or failure. Compared to team success, we expected the degree of ingroup identification to predict specific experienced emotions, and for this to be particularly the case following a loss, an intergroup threat in this context.

We expected identification to predict qualitatively different emotions due to different appraisals of the general context at hand (i.e. a team loss). Above we discussed how the perception of the ingroup as being in either a strong or weak position can lead to different appraisals of the same situation, and correspondingly different emotions and action tendencies (Mackie et al., 2000; Silver et al., 2001). Specifically, when the ingroup is in a strong position relative to the outgroup, this should elicit approach-related emotions, leading to offensive action tendencies toward the outgroup. In contrast, when the ingroup is in a weaker position relative to the outgroup, this should elicit withdrawal-type emotions, resulting in avoidance of the outgroup. For several reasons we believe it is reasonable to equate perceiving either a strong or weak position relative to the outgroup with ingroup identification. According to social identity theory's self-esteem hypothesis (Abrams \& Hogg, 1988), people can use group membership as a resource-as a means of acquiring positive self-esteem. This tendency appears to vary as a function of identification. Martinot, Redersdorff, Guimond, and Dif (2002) found that identification mediated the extent to which group members self-categorized to protect themselves from threatening comparisons (and retain positive self-esteem, Redersdorff \& Martinot, 2003). Similarly, the negative impact of perceiving oneself to be victim of discrimination can be alleviated by higher ingroup identification (Branscombe, Schmitt, \&
Harvey, 1999). Arguably these examples of people identifying with groups as a way of dealing with threat suggest that for such perceivers the ingroup must be seen as a source of strength. Put another way, groups are seen as stronger, more potent, and better able to serve as a viable source of positive self-esteem to the extent that one identifies with the group.

We may therefore expect, as with higher perceived group strength, that higher identifiers will be more inclined (than lower identifiers) to feel angry following a threat, and to be more inclined to report tendencies toward approach, aggression-related behaviors (consistent with Mackie et al., 2000). As we have noted, higher identifiers are more likely to be ingroup protective under threat, showing bolstering behaviors like stereotyping, ingroup homogenization, self-stereotyping and bias. Approach-type behaviors, and by association the experience of angry emotions, are consistent with these general trends. Indeed, Wann and Branscombe (1990) found that highly identified sports team fans were less likely to Cut Off Reflected Failure (CORF) than low identifiers, arguing that they instead use other coping mechanisms when they lose, such as expressing anger, hostility and aggression.

Anger and approach behaviors therefore seem consistent with what we already know about how high identifiers react to ingroup threat. But what about lower identifiers? Typically we might expect lower identifiers to simply exhibit less intense behaviors than higher identifiers (their identity is less bound up with their group's successes or failures). They are less likely to react with ingroup-bolstering or protective behaviors than higher identifiers (e.g. ingroup favoritism) and are more likely to try alternative self-esteem maintenance/restoration techniques, such as dis-identifying and individuating themselves (Ellemers, van Knippenberg, \& Wilke, 1990; Ellemers, Wilke, \& van Knippenberg, 1993; Martinot et al., 2002). Based on what we know about lower identifiers in general we might therefore not predict any qualitative difference in specific emotion experienced, but rather simply a less intense reaction to that of higher identifiers. 
In the context of sports team allegiance, however, there is a critical difference to much of the existing work on the moderating impact of ingroup identification. That is that members in these contexts have chosen their allegiance to a particular identity, and, as fans, should show a general positively skewed level of identification with the team. That is, sports fans should all be fairly committed to the group. In this context, the terms lower and higher identification take on a new meaning, but a meaning that is consistent with our prediction of a qualitative dissociation of specific emotions.

While typically we might regard people who are lower identifiers with groups to simply feel less intensely about threats to that identity, here we might expect a qualitatively different experience for people who all feel a negative emotion. Importantly, given the skew toward high commitment, we expect all fans will experience a negative emotion following a loss, but the type of emotion experienced will depend upon how committed a fan they are. Consistent with the findings from Sloan (1989) this represents a key conceptual distinction between affiliations that are freely chosen and developed, like sports team allegiance-identities that matter to all members of the group-and types of groups that are not chosen by participants (such as gender and race) which can engender very low levels of commitment (indeed for such groups dis-identification can be observed, when people try to distance themselves from what they might perceive to be a devalued identity; Steele \& Aronson, 1995). As such, the positive skew toward high identification is representative of a precondition required to observe the qualitative differentiation of emotions we predict here.

Given that sporting contexts are typically those where all members have a baseline level of commitment, we may therefore expect the degree of identification reported by fans to predict different forms of experienced negative affect. Lower identifying fans should feel negative but they should feel specifically more sad-a less action-oriented emotion-than higher identifiers, and so be more inclined to want to avoid the outgroup. We can equate this with previous work which has found that being in a weaker position predicts avoidance action tendencies and related emotions (Mackie et al., 2000; Silver et al., 2001). Here we expect not fear, but a different negative emotion, sadness, to evoke avoidance. We would not expect fear to be particularly applicable in a sports-fan context because it is an emotion that is typically elicited when thinking about future negative events: Here, sports fans are appraising a negative event that has happened in the past-a match loss. From research on counterfactual thinking we know that thinking about negative past events can elicit negative affect (Roese, 1997), and, in particular, this negative affect is characterized by sadness (Mandel, 2003). The idea that sadness should lead to avoidance is consistent with Neuberg and Cottrell (2002) who argue that sadness is associated with self-contemplation and selfimposed seclusion (for a similar argument see Crisp, Ensari, Hewstone, \& Miller, 2002). This dissociation in predicted emotional reactions is also consistent with what we know of lower identifiers in threatening group contexts. It is lower identifiers who will be most likely to 'cut off reflected failure' (Snyder et al., 1986), via avoidance arising from associated emotions like sadness. While lower identifying fans are likely to feel negative about a loss like higher identifiers, their reaction will be more associated with distancing themselves, rather than engaging in ingroup-protective behavior, and this will be reflected in their action tendencies.

In sum, we argue that while all participants will experience negative affect following a loss (all being fans with a baseline skew toward higher levels of identification), the nature of how this negative affect is experienced and represented in behavioral tendencies will vary as a function of the degree of identification above this baseline. Consistent with the above theory and empirical findings, lower identifying fans will react to the loss with CORF-like tendencies such as avoidance, and they will experience avoidance-related emotions such as sadness. As identification rises for these fans we expect more anger-related and aggressive approach tendencies to be exhibited, consistent with what we know of the ingroup bolstering reactions to threat observed in previous 
studies. In the study reported below, we tested these predictions.

\section{Method}

\section{Participants and design}

Sixty male soccer supporters participated in this study; their ages ranged from 16 to 52 years. All participants were fans of Northfield Town Football Club, a small amateur club in the city of Birmingham, England. Founded in 1966, they play in the Midland Combination League. Fans were sampled on three occasions $\left(N_{\mathrm{s}}=16\right.$, 23 and 21), following one win (score: $1-0)$ and two losses $(0-3 ; 0-2)$ for their team. As such, win or loss constituted a dichotomous betweensubjects variable, and identification a continuous predictor for anger, sadness and happiness emotions, and approach and avoidance action tendencies.

\section{Dependent measures}

Intergroup emotion Our measure of intergroup emotion (adapted from Mackie et al., 2000), was intended to measure participants' emotional reactions (anger, sadness and happiness) to the results of each match. Participants were asked to state the result of the match before rating their emotions about the result using a 7-point Likert scale, ranging from 1 (not at all) to 7 (very much so). The emotions participants were asked to rate were: angry, hostile, annoyed, irritated, furious (measuring anger; $\alpha=.967) ; \mathrm{sad}$, depressed, tense, distressed, upset (measuring sadness; $\alpha=.947)$; and happy, pleased, cheerful, calm, elated (measuring happiness; $\alpha=.883$ ).

Action tendencies To measure the extent to which different emotions would facilitate different behaviors, we also adopted the measure of action tendencies used by Mackie et al. (2000). These measures are useful because while social psychologists typically focus on negative evaluations of a group and its members, such measures are limited because they do not explain the wide variety of reactions to the outgroup. Action tendencies, group members' desire to behave in a particular way toward the outgroup, may help us to understand a broader range of reactions to other groups. We were interested in measuring two specific action tendencies; the tendency to move toward the outgroup and the tendency to move away from it, which we hypothesized would be associated with anger and sadness respectively. The tendency to move toward the outgroup was measured by two items asking participants to rate the extent to which the result of the match made them want to: 'Confront the opposition's fans', and 'Argue with the opposition's fans', which were significantly correlated with one another $(r(60)=.86, p<.0001)$. These items were therefore averaged to form a single index of approach tendency. The tendency to avoid the outgroup was measured by two items, asking participants to rate the extent to which the result of the match made them want to, 'Avoid the opposition's fans', and 'Have nothing to do with them', which were also highly correlated $(r(60)=.68, p<.0001)$. These two items were therefore averaged to form a single index of avoidance. Participants responded to all four items on a 7-point Likert scale, ranging from 1 (not at all) to 7 (very much so).

\section{Procedure}

The questionnaire was designed following consultation with a number of soccer fans about the nature of supporter behavior at soccer matches. The study was carried out at the soccer team's ground when home games were being played. Sixty participants were tested over a three match period, being told that the purpose of the study was to 'gain information about how people think about their team for research into spectator behavior'. At the end of each soccer match, participants were approached by the experimenter as they left the soccer ground and asked if they would complete a voluntary questionnaire. An introductory page, covering issues of informed consent and confidentiality, and giving a brief explanation of the research area was first presented. Participants were then asked to complete items relating to ingroup identification. These items asked participants to rate the extent to which they agreed with the following four statements (adapted from Jetten, Branscombe, Spears \& McKimmie, 2003; 
Luhtanen \& Crocker, 1992): 'I identify strongly with other Northfield Town FC supporters', 'Being a Northfield Town FC supporter is an important part of who I am', 'I feel strong ties with other Northfield Town FC supporters', 'I feel a sense of solidarity with Northfield Town FC supporters' (1-not at all, 9-very much). These items formed a reliable index $(\alpha=.976)$ so were averaged accordingly to form a single measure of identification. Following this, participants completed the intergroup emotions items, noting first their team's final score and the opposing team's final score (to reinforce the win-loss threat context). Finally, the participants completed the action tendency items before being thanked and debriefed.

\section{Results}

We used moderated regression (Aiken \& West, 1991) to investigate the impact of a threat to the ingroup (loss vs. win) on intergroup emotions and action tendencies as a function of ingroup identification. We computed an interaction variable by contrast coding our threat conditions as 0 and 1 (loss vs. win) and multiplying it by the centered continuous identification scores for each participant. We then entered this interaction variable into a multiple regression on a second step following the insertion of the categorization and identification factors independently at step 1 . Notably, mean identification did not vary over sampling sessions $(F(2,57)=.280, p=.757)$ $(M \mathrm{~s}=4.76,5.17,4.73)$ and across all sessions the overall identification mean was $4.86(S D=1.94)$ which was significantly higher than the midpoint of the scale $(4)(t(59)=3.43, p=.001)$. This confirmed the expected positive skew of the identification scores in this context.

\section{Intergroup emotions}

We first computed two indices: anger plus sadness, and anger minus sadness. This created the variables needed to test whether there was an interaction between result, identification and specific emotion. The anger minus sadness index equates to entering anger and sadness as different levels of an emotion within-subjects factor in a typical analysis of variance (ANOVA); effects on the anger plus sadness index equate to between-subjects effects observed in a typical ANOVA. For our purposes of differentiating specific types of emotion, the former index is most relevant here. The procedure involving the anger minus sadness index creates what is essentially a within-subjects factor of emotion (anger vs. sadness) and effects on this index indicate diverging trends to report anger and sadness emotions respectively. Interactions can then be decomposed like any other higher-order ANOVA interaction by carrying out the separate analyses for the two levels of the emotion factor (sadness and anger).

This analysis revealed that, overall, as identification increased so too did general negative affect (anger plus sadness) $(\beta=.262 ; t=2.90$, $p=.005$ ). In addition, negative affect (anger plus sadness) was greater following a loss than a win, irrespective of degree of ingroup identification $(\beta=-.713 ; t=-7.89, p<.0005)$. There was no result $\times$ identification interaction on general negative affect (anger plus sadness) $(\beta=.059$; $t=.185, p=.854)$. These findings confirm that, overall, higher and lower identifiers felt equally negative following a loss compared to a win.

These between-subjects effects (using the anger plus sadness index) were qualified, however, by several interactions that show a dissociation of the different types of emotion (using the anger minus sadness index). There was a result $\times$ emotion interaction $(\beta=-.244$; $t=-2.47, p=.017)$, and an identification $\times$ emotion interaction $(\beta=.648 ; t=6.55, p<.0005)$. The latter indicated that degree of ingroup identification was positively related to anger $(\beta=.506 ; t=4.46, p<.0005)$, while degree of identification was negatively related to sadness $(\beta=-.321 ; t=-2.58, p=.012)$. Broadly, this supports the notion that ingroup identification will differentiate intergroup emotions: at higher levels of identification participants reported more anger, and at lower levels of identification participants reported more sadness. Both of these effects were qualified by the predicted result $x$ identification $\times$ emotion interaction $(\beta=-.985$; $t=-3.06, p=.003)$. This interaction suggested that participants reported qualitatively different emotions depending on their degree of ingroup 
identification following losses versus wins. To decompose this interaction, we examined the effects of result and identification on anger and sadness separately.

Anger Moderated regression analysis revealed that as identification increased so too did anger $(\beta=.566 ; t=7.06, p<.0005)$. In addition, anger was greater following a loss than a win, irrespective of degree of ingroup identification $(\beta=-.620 ; t=-7.72, p<.0005)$. These effects were qualified, however, by the predicted result $\times$ identification interaction $(\beta=-.559$; $t=-2.05, p=.045$ ) (see Figure 1). Simple slope analysis within result condition revealed that identification had a marginal effect on anger when the soccer team had won the match $(\beta=.417 ; t=1.72, p=.11)$, but was significantly positively related to anger when the soccer team had lost the match $(\beta=.720$; $t=6.73, p<.0005)$. The higher the participants identified with their team, the more anger they experienced following a loss.

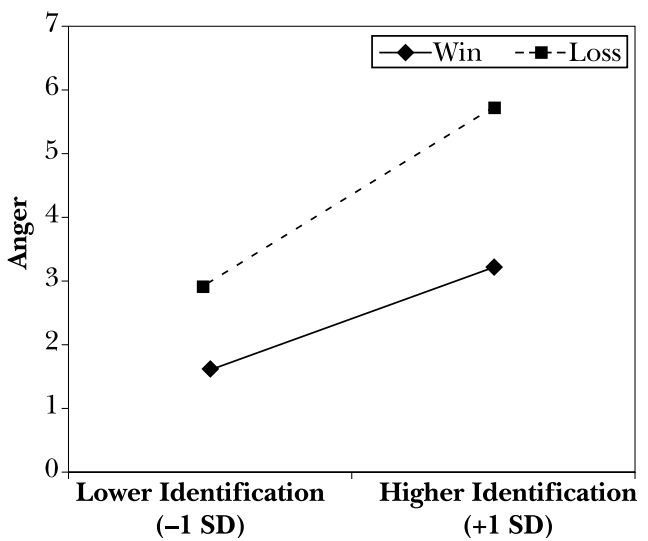

Figure 1. Reported anger as a function of threat and ingroup identification.

Sadness Moderated regression analysis revealed that as identification increased sadness decreased $(\beta=-.281 ; t=-2.47, p=.02)$. In addition, sadness was greater following a loss than a win, irrespective of degree of ingroup identification $(\beta=-.413 ; t=-3.64, p=.001)$. These effects were qualified, however, by the predicted result $\times$ identification interaction $(\beta=.813$; $t=2.11, p=.039$ ) (see Figure 2). Simple slope analysis within result conditions revealed that identification had a marginal positive relationship with sadness when the soccer team had won the match $(\beta=.440 ; t=1.83$, $p=.088$ ), but a significant negative relationship with sadness when the soccer team had lost the match $(\beta=-.401 ; t=-2.84, p=.007)$. The less the participants identified with their team, the more sadness they experienced following a loss-a qualitatively different relationship than that observed between identification and anger, which was a positive relationship.

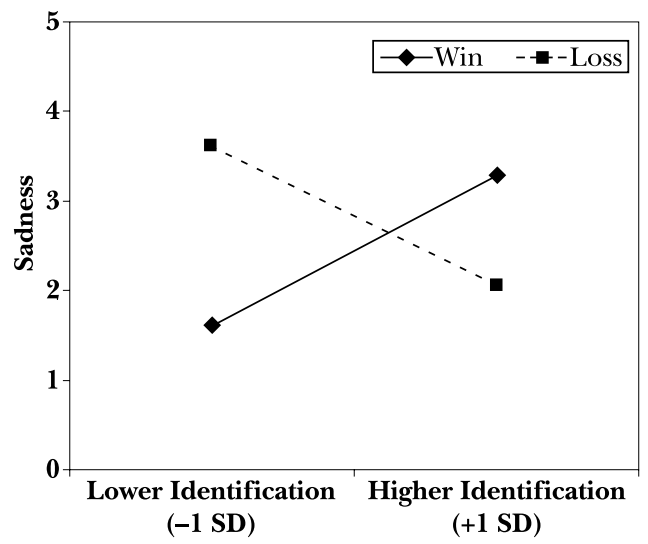

Figure 2. Reported sadness as a function of threat and ingroup identification.

\section{Action tendencies}

We first computed two indices: avoidance plus approach, and avoidance minus approach. This created the variables needed to test whether there was an interaction between result, identification and action tendencies. This analysis revealed only two theoretically significant effects. First, there was an identification $x$ action tendency interaction $(\beta=.581 ; t=5.35$, $p<.0005)$. This interaction indicated that while degree of ingroup identification was positively related to approach tendencies $(\beta=.579$; $t=5.40, p<.0005)$, it was negatively related to avoidance tendencies $(\beta=-.289 ; t=-2.30$, $p=.025)$. This supports the basic hypothesis that degree of identification will differentiate 
action tendencies: higher identifiers tended toward approach behaviors, lower identifiers tended toward avoidance behaviors.

These effects were qualified, however, by a result $\times$ identification $\times$ action tendency interaction that approached significance $(\beta=-.635$; $t=-1.70, p=.094)$. This interaction suggested that participants reported qualitatively different action tendencies depending on their degree of ingroup identification following losses versus wins. To decompose this interaction, we examined the effects of result and identification on the two action tendencies separately.

Approach action tendency As identification increased so too did tendencies to approach the outgroup $(\beta=.609 ; t=6.08, p<.0005)$. In addition, tendencies to approach were greater following a loss than a win, irrespective of degree of ingroup identification $(\beta=-.313 ; t=3.12$, $p=.003)$. These effects were not qualified by a result $\times$ identification interaction $(\beta=-.129$; $t=-.366, p=.716)$, indicating that as identification increased, so too did approach tendencies, both when the team had lost a match, but also when the team had won a match (see Figure 3).

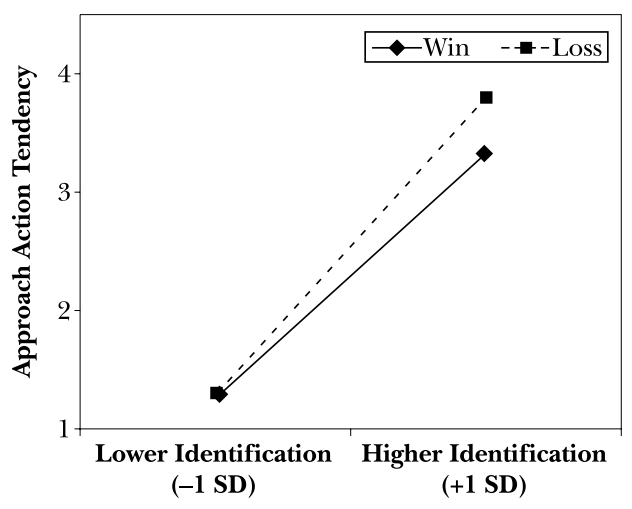

Figure 3. Reported approach tendencies as a function of threat and ingroup identification.

Avoidance action tendency As identification decreased tendencies to avoid the outgroup increased $(\beta=-.268 ; t=-2.16, p=.035)$. In addition, there was a marginal tendency to report more avoidance of the outgroup following a loss than a win, irrespective of degree of ingroup identification $(\beta=.221$; $t=1.78, p=.080)$. These effects were, however, qualified by a result $\times$ identification interaction $(\beta=.854 ; t=2.03, p=.048)$ (see Figure 4). Simple slope analysis within result condition revealed that identification had a marginal positive relationship with avoidance when the team had won the match, $\beta=.429 ; t=1.78, p=.098$. When the soccer team had lost the match, however, there was a significant negative relationship between identification and avoidance, $\beta=-.367$; $t=-2.55, p=.014$. Lower identifiers were more likely to avoid the outgroup than high identifiers following a loss.

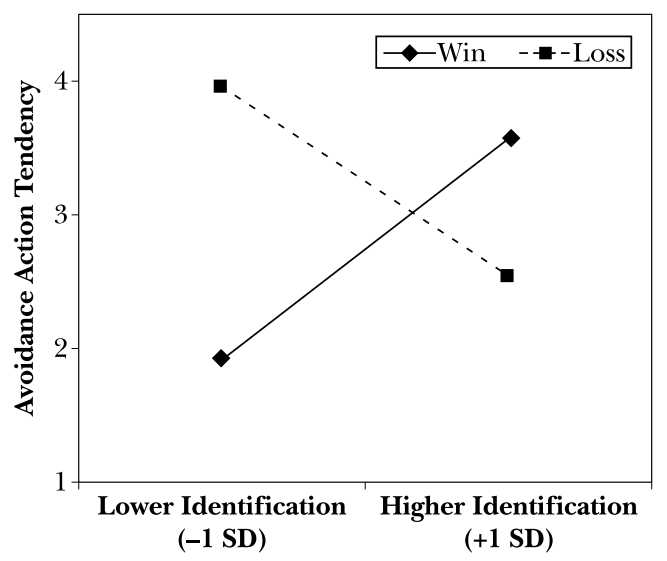

Figure 4. Reported avoidance tendencies as a function of threat and ingroup identification.

\section{Mediational analysis}

We computed mediational analyses to assess whether the relationship between ingroup identification and the tendency to approach or avoid the outgroup could be explained by anger and sadness respectively following a match loss. Regarding the effect of identification on the tendency to approach the outgroup, in step 1, the outcome measure (approach tendency) was regressed onto the predictor (identification). This analysis revealed a significant relationship between the predictor and the outcome $(\beta=.643 ; p<.0005)$. In step 2 , the analysis revealed a significant relationship between 
identification and the potential mediators, anger $(\beta=.720 ; p<.0005)$ and sadness $(\beta=-.401$; $p=.007)$. In step 3 , approach behavior was regressed onto the mediators while controlling for identification. This analysis revealed that while there was a significant relationship between anger and approach tendency $(\beta=.909 ; p<.0005)$, there was not between sadness and approach tendency $(\beta=-.057 ; p=.453)$. Finally, when the mediators were controlled in the first equation, the relationship between the predictor and the outcome became nonsignificant $(\beta=-.034$; $p=.742)$, and a Sobel test was significant $(z=5.43$; $p<.0005)$ see Figure 5 top). In sum, although identification predicted both anger and sadness, it was only anger that mediated the effect of identification on the tendency to approach the outgroup.

We next computed a mediational model of the effect of identification on the tendency to avoid the outgroup. In step 1, the outcome measure (avoidance) was regressed onto the predictor (identification). This analysis revealed a significant relationship between identification and avoidance $(\beta=-.367 ; p=.014)$. In step 2 , the analysis revealed a significant relationship between identification and potential mediators, sadness $(\beta=-.401 ; p=.007)$ and anger $(\beta=.720$; $p<.0005$. In step 3 , avoidance was regressed onto the mediators while controlling for identification. This analysis revealed a significant relationship between sadness and avoidance $(\beta=.897 ; p<.0005)$, but not anger and avoidance $(\beta=.028 ; p=.78)$. Finally, when the mediators were controlled in the first equation, the relationship between identification and avoidance became nonsignificant $(\beta=-.027$; $p=.797)$, and a Sobel test was significant $(z=$ $2.75 ; p=.006$ ) (see Figure 5 bottom). In sum, although identification positively predicted both anger and sadness, only sadness mediated the effect of identification on avoidance following a match loss. These distinct mediational paths identified for approach and avoidance action tendencies further support the dissociation of emotions and action tendencies as a function of identification. ${ }^{2}$

\section{Discussion}

In this research we set out to integrate work on the distinctive reactions of lower and higher identifiers in social judgment with intergroup emotions theory. In the context of soccer fans' reactions to wins or losses, we measured negative, but qualitatively distinct, intergroup emotions and action tendencies. Broadly, we found strong support for the overall dissociation of emotions and action tendencies as a function of ingroup identification. Anger was experienced to a greater extent for higher identifiers than lower identifiers, and sadness was experienced to a greater extent for lower identifiers than higher identifiers. These tendencies were, however, qualified by threat (consistent with previous work on social identity theory), here contextualized as a team win or loss. When participants' group identity was threatened (a loss), qualitatively different emotional responses were observed for higher and lower identifiers: higher identifiers were more angry than lower identifiers, whereas lower identifiers were more sad than higher identifiers. Identification with the ingroup also predicted differences in the tendency to approach or avoid the outgroup following a loss: lower identifiers were more likely to avoid the outgroup than higher identifiers after a loss; higher identifiers were more likely to approach the outgroup than lower identifiers after a loss (although this latter tendency was also observed when the ingroup team had won). Crucially, the effect of identification on action tendencies after a loss was fully mediated only by the specific associated emotion: approach tendencies were mediated by anger, not sadness; avoidant tendencies were mediated by sadness, but not anger. More generally we supported the basic positive relationship between identification and anger (and consequent approach tendencies) and the basic negative relationship between identification and sadness (and consequent avoidance tendencies). These findings support intergroup emotions theory, which proposes that specific emotions are associated with specific action tendencies, but they also show that these 


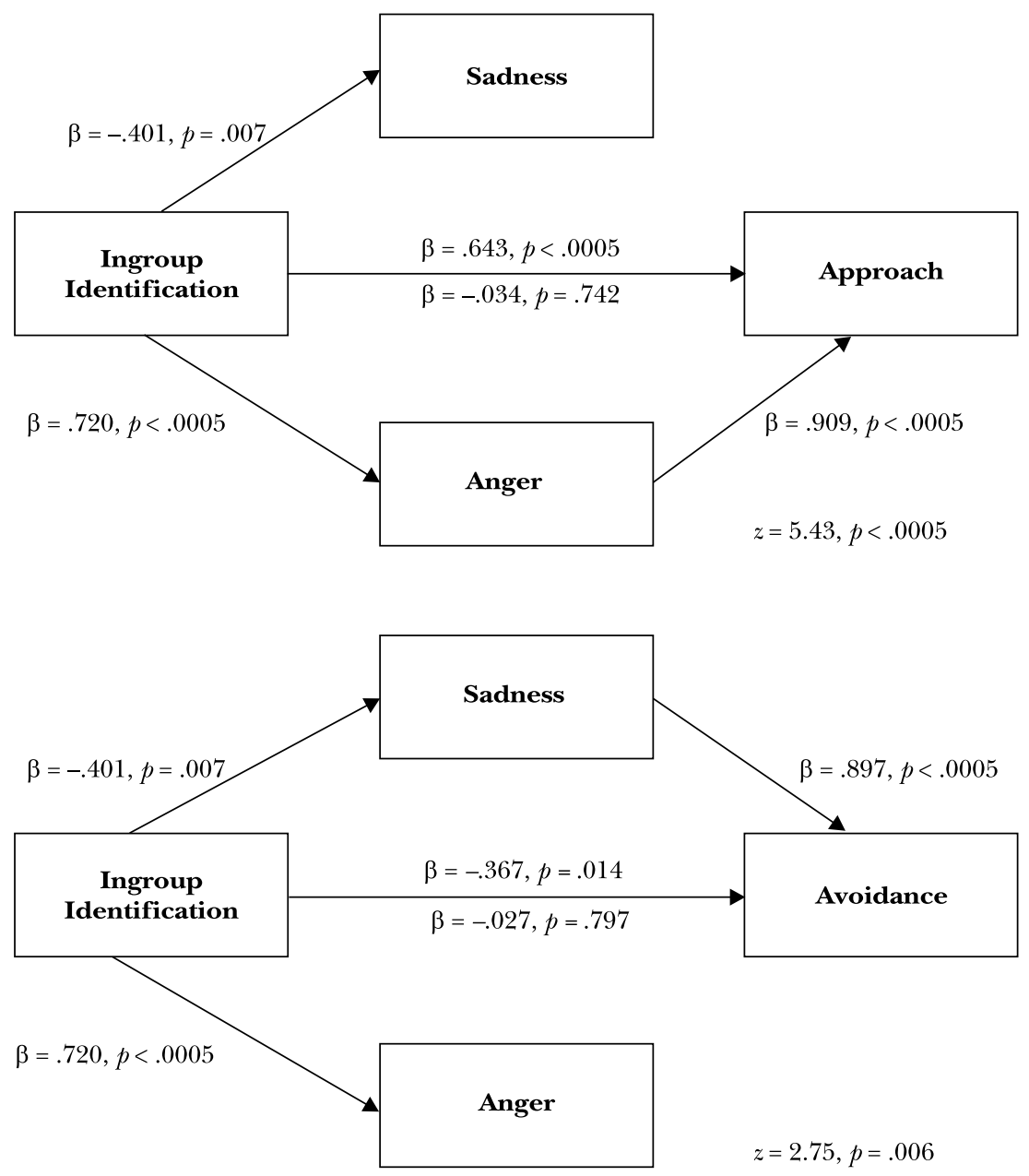

Figure 5. Top: mediational model of the role of reported anger in explaining the identification-approach action tendency relationship following a match loss. Bottom: mediational model of the role of sadness in explaining the identification-avoidance action tendency relationship following a match loss.

mediational paths are moderated by ingroup identification. Below we discuss the implications of these findings for intergroup emotions theory, social identity theory and efforts to apply social psychological theory to real intergroup contexts such as those involving sports fan behavior.

\section{Theoretical implications}

The current findings provide strong support for intergroup emotions theory (Mackie et al., 2000;
Smith, 1993, 1999). When group membership as a soccer fan was salient as a result of watching a soccer match with another team, participants reacted emotionally to losing the match, a situation that affected the ingroup. For lower identifiers, moreover, losing a soccer match led to the action tendency of outgroup avoidance, an effect mediated by the emotional reaction of sadness; for higher identifiers losing a match led to outgroup approach behaviors, an effect 
mediated by anger. While previous research has shown that contempt (Mackie et al., 2000) and fear (Silver et al., 2001) led to an action tendency of avoidance, we believe the current study is the first to show a sadness-avoidance link, and in particular that sadness mediates the relationship between identification and an action tendency to avoid the outgroup. Although sadness was not specified in the original theory as a mediator of the effect of an appraisal about the intergroup context on avoidance of the outgroup, we associate sadness with withdrawal from social situations (see Crisp et al., 2002). Summarizing research on the associations between specific intergroup emotions and action tendencies, Neuberg and Cottrell (2002) concluded that sadness was associated with self-contemplation and self-imposed seclusion. It therefore makes sense that sadness emerged as a mediator of the relationship between identification and avoidance.

It is important to note that our findings here apply to a context where all members are to some extent highly committed. Soccer fans (and more generally sports fans), by definition, may have a baseline level of identification above which they can vary, and this may represent a context distinct from that in which identification has been studied previously. On the one hand this is a potentially important boundary condition defining when the dissociation of qualitatively different emotions might be observed, but it also opens up a potentially new and exciting avenue for future research in which definitions of ingroup identification can become more fine-grained, potentially revealing a more qualitatively detailed picture of the implications of commitment to groups. Broadly speaking, these findings imply that identification can not only predict differences in the intensity of responses but can also sometimes reveal more fine-grained, specific affective or behavioral tendencies in particular intergroup contexts, such as those relating to sports team allegiance, where affiliation has been adopted as a potential means of providing self-conceptual benefits.

Intergroup emotions theory is grounded in social identity theory; Smith (1993) proposed that intergroup—rather than individual level- emotions would only arise when social identity was salient. The current findings strengthen the link between intergroup emotions theory and social identity theory by demonstrating that ingroup identification moderates the effect of a threat to the ingroup on intergroup emotions. Specifically, they showed that threat to the ingroup led to anger for high identifiers and sadness for low identifiers. Previous research has focused on the effects of the intergroup context in producing different intergroup emotions, showing, for example, that when the ingroup is in a strong position, there is anger and aggression toward the outgroup, but when the ingroup is in a weak position, there is fear and avoidance of the outgroup (Mackie et al., 2000). In contrast, we have found that characteristics of the group members themselves influence which intergroup emotions arise. Enhancing our understanding of the factors that moderate when specific intergroup emotions and associated action tendencies will arise represents an important development in intergroup emotions theory.

Finally, we know that variability in ingroup identification is a reliable predictor of a wide range of intergroup attitudes (ranging from self-stereotyping to intergroup bias, e.g. Jetten et al., 2004). This research has added a specific dissociation of emotions and action tendencies to this list. Higher identification, as well as leading to more self-stereotyping, homogeneity and intergroup bias, also appears specifically to lead to more anger and approach behaviors. Lower identification, as well as leading to a greater tendency to individuate oneself and dissociate from the ingroup, appears to specifically lead to more sadness and avoidance tendencies, especially under threat. It is this qualitative dissociation that is particularly interesting here, supporting the general notion that lower and higher identifiers think and act differently in intergroup contexts.

\section{Sport and social identity}

The findings of the present study have important implications for future research within the field of soccer-related types of social disorder which seeks to uncover systemic intergroup processes using experimental social psychology 
approaches, but which strives to keep at its center the socially situated affective experiences of the participants. The integration of selfcategorization and social identity principles with intergroup emotions theory is promising for future developments in this applied field, because it incorporates the particular acute affective states felt by, and described by, those who routinely attend soccer matches. Indeed, we believe that this is the first field test of the processes outlined by intergroup emotions theory.

Marsh, Rosser, and Harré's (1978) expositive analysis of soccer-related disorder in the UK in the late 1970 s was timely because of the difference between the widely received view of the phenomenon in question and what they observed through social scientific methods. They argued that the public perception of disorder at soccer matches (shaped through political and media rhetoric) was that it was chaotic and irregular, the sum total of a large number of uneducated aggressive hooligans behaving erratically and nonnormatively. To some extent, all British soccer supporters-but particularly those designated 'hooligans'-were subject to a degree of infrahumanization at that time, and this state of affairs was exacerbated by the attitude of the right-wing press and government in the 1980s. 'Hooligans' were being categorized as distinct creatures from 'normal people'. Intraindividual, rather than intergroup, processes, were to blame. This in itself might have made it possible to dismiss social-level processes from being applicable on the many occasions on which social disorder was taking place. Our study suggests that soccer's quite particular emotional thesaurus is evident at a personal level and is linked to what can be termed loosely as disorder-facilitating (not causing) 'approach' tendencies, but stems from a social-level process.

The perception of soccer supporters in society is very different in 2005 following a change in the game's spectator demographics (more women and children following perceived safety improvements in stadia, 'middle-class' cultural acceptability since the early 1990s, season tickets becoming prohibitively expensive for low income families). As such, social disorder attached to soccer is, increasingly, less credibly attached to widespread 'hooliganism'. As a consequences of this, intergroup process explanations of such incidents now have greater explanatory power. Stott et al.'s (2001) ethnographic study of the 1998 World Cup seems to confirm this point; they argue that their findings show that, '.. it is simply not adequate to see all violence... purely and exclusively in terms of the presence and predisposition of hooligans' (p. 379). While Marsh et al.'s (1978) social anthropological observations are rooted in the decade they were made, their argument regarding the highly structured and rule-based nature of social behavior at soccer matches still rings true. Such a structured and organized intergroup environment is a dream setting in which to apply and test intergroup emotions theory; there is no question that group membership is highly salient and situations are being constantly evaluated in terms of their repercussions for the ingroup.

\section{Conclusion}

In this research we argue that emotions and action tendencies can be qualitatively differentiated depending on the extent to which people see the relevant ingroup as being important for their self-concept. The data we report here support this hypothesis. Following match losses lower identifiers felt sad but not angry, whereas higher identifiers felt angry but not sad and these negative, but qualitatively different, emotional reactions mediated reported action tendencies. The findings support the basic links between specific emotion and action tendency outlined by intergroup emotions theory, as well as providing a point of synthesis with existing work on the importance of social identification in describing and defining intergroup relations. This work may therefore aid the development of an elaborated account of the motivational and emotive processes that define thought and behavior in social contexts.

\section{Notes}

1. We also carried out the moderated regression analysis on the items that formed the happiness 
index and found the same result $\times$ identification interaction $(\beta=.566 ; t=2.32, p=.024)$, with simple slope analysis revealing that identification did not significantly affect happiness when the participants' soccer team had won the match $(\beta=.351 ; t=1.41, p<.18)$, but was negatively related to happiness when the soccer team had lost the match $(\beta=-.418 ; t=-2.98, p<.005)$. Happiness is not, however, relevant to the theoretical aims of the current research, so we do not discuss these findings in detail.

2. We also tested these mediational models irrespective of intergroup threat (win or loss) and observed a replication of all paths found to be significant above.

\section{References}

Abrams, D., \& Hogg, M. A. (1988). Comments on the motivational status of selfesteem in social identity and intergroup discrimination. European Journal of Social Psychology, 18, 317-334.

Abrams, D., \& Hogg, M. A. (1998). Prospects for research in group processes and intergroup relations. Group Processes Intergroup Relations, 1, 7-20.

Aitken, L. S., \& West, S. G. (1991). Multiple Regression: Testing and interpreting interactions. London: Sage.

BBC News Online (2005). City's tribute to bombing victims. Retrieved November 29, 2005 from http://news.bbc.co.uk/1/hi/england/west_ yorkshire/4682739.stm.

Branscombe, N. R., Schmitt, M. T., \& Harvey, R. D. (1999). Perceiving pervasive discrimination among African Americans: Implications for group identification and well-being. Journal of Personality and Social Psychology, 77, 135-149.

Branscombe, N., \& Wann, D. (1994). Collective self-esteem consequences of outgroup derogation when a valued social identity is on trial. European Journal of Social Psychology, 24, 641-657.

Branscombe, N. R., Wann, D. L., Noel, J. G., \& Coleman, J. (1993) In-group or out-group extremity: Importance of the threatened social identity. Personality and Social Psychology Bulletin, 19, 381-388.

Brown, R., \& Williams, J. (1984). Group identification: The same thing to all people? Human Relations, 7, 547-564.

Cialdini, R. B., Borden, R. J., Thorne, A., Walker, M. R., Freeman, S. \& Sloan, L. R. (1976). Basking in reflected glory: Three football field studies. Journal of Personality and Social Psychology, 34, 366-375.

Crisp, R. J. (2006). Commitment and categorization in common ingroup contexts. In R. J. Crisp \& M. Hewstone (Eds.), Multiple social categorization: Processes, models and applications (pp. 90-111). Hove, E. Sussex, UK: Psychology Press (Taylor \& Francis).

Crisp, R. J., Ensari, N., Hewstone, M., \& Miller, N. (2002). A dual-route model of crossed categorization effects. In W. Stroebe \& M. Hewstone (Eds.), European Review of Social Psychology (Vol. 13, pp. 35-74). Philadelphia: Psychology Press.

Crisp, R. J., \& Hewstone, M. (2006). Multiple social categorization: Context, process, and social consequences. In R. J. Crisp \& M. Hewstone (Eds.), Multiple social categorization: Processes, models and applications (pp. 3-22). Hove, E. Sussex, UK: Psychology Press (Taylor \& Francis).

Crisp, R. J., Stone, C. H., \& Hall, N. R. (2006). Recategorization and subgroup identification: Predicting and preventing threats from common ingroups. Personality and Social Psychology Bulletin, 32, 230-243.

Devos, T., Silver, L. A., Mackie, D. M., \& Smith, E. R. (2002). Experiencing intergroup emotions. In D. M. Mackie \& E. R. Smith (Eds.), From prejudice to intergroup emotions: Differentiated reactions to social groups (pp. 113-134). Philadelphia: Psychology Press.

Doosje, B., Ellemers, N., \& Spears, R. (1995). Perceived intragroup variability as a function of group status and identification. Journal of Experimental Social Psychology, 31, 410-436.

Ellemers, N., Spears, R., \& Doosje, B. (1997). Sticking together or falling apart: In-group identification as a psychological determinant of group commitment versus individual mobility. Journal of Personality and Social Psychology, 72, 617-626.

Ellemers, N., van Knippenberg, A., \& Wilke, H. A. (1990). The influence of permeability of group boundaries and stability of group status on strategies of individual mobility and social change. British Journal of Social Psychology, 29, 233-246.

Ellemers, N., Wilke, H., \& van Knippenberg, A. (1993). Effects of the legitimacy of low group or individual status on individual and collective status-enhancement strategies. Journal of Personality and Social Psychology, 64, 766-778. 
Fédération Internationale de Football Association. (n.d.). Retrieved November 16, 2005, from http://www.fifa.com/en/organisation/president section/0,1650,2,00.html.

Frijda, N. H. (1986). The emotions. Cambridge, UK: Cambridge University Press.

Hinkle, S., \& Brown, R. (1990). Intergroup comparisons and social identity: Some links and lacunae. In D. Abrams \& M. Hogg (Eds.), Social identity theory: Constructive and critical advances. Hemel Hempstead, UK: Harvester Wheatsheaf.

Hirt, E. R., Zillmann, D., Erickson, G. A., \& Kennedy, C. (1992). Costs and benefits of allegiance: Change in fans' self-ascribed competencies after team victory versus defeat. Journal of Personality and Social Psychology, 63, 724-738.

Hogg, M. A., \& Abrams, D. (1988). Social identifications: A social psychology of intergroup relations and group processes. London: Routledge.

Hogg, M. A., \& Abrams, D. (1990). Social motivation, self-esteem, and social identity. In D. Abrams \& M. A. Hogg (Eds.), Social identity theory: Constructive and critical advances (pp. 28-47). Hemel Hempstead, UK: Harvester Wheatsheaf.

Jetten, J., Branscombe, N. R., Spears, R., \& McKimmie, B. M. (2003). Predicting the paths of peripherals: The interaction of identification and future possibilities. Personality and Social Psychology Bulletin, 29, 130-140.

Jetten, J., Spears, R., \& Postmes, T. (2004). Intergroup distinctiveness and differentiation: A meta-analytic integration. Journal of Personality and Social Psychology, 86, 862-879.

Luhtanen, R., \& Crocker, J. (1992). A collective self-esteem scale: Self -evaluation of one's social identity. Personality and Social Psychology Bulletin, 18, 302-318.

Mackie, D. M., Devos, T., \& Smith., E. R. (2000). Intergroup emotions: Explaining offensive action tendencies in an intergroup context. Journal of Personality and Social Psychology, 79, 602-616.

Mandel, D. R. (2003). Counterfactuals, emotions, and context. Cognition and emotion, 17, 139-159.

Marsh, P., Fox, K., Carnibella, G., McCann, J., \& Marsh, J., (1996). Football violence in Europe. Amsterdam: The Amsterdam Group.

Marsh, P., Rosser, E., \& Harré, R. (1978). The rules of disorder. London: Routledge and Kegan Paul.

Martinot, D., Redersdorff, S., Guimond, S., \& Dif, S. (2002). Ingroup versus outgroup comparisons and self-esteem: The role of group status and ingroup identification. Personality and Social Psychology Bulletin, 28, 1586-1600.

Neuberg, S. L., \& Cottrell, C. A. (2002). Intergroup emotions: A biocultural approach. In D. M. Mackie \& E. R. Smith (Eds.), From prejudice to intergroup emotions: Differentiated reactions to social groups (pp. 265-283). Philadelphia: Psychology Press.

Redersdorff, S., \& Martinot, D. (2003). Impact of upward and downward social comparisons on self-esteem: Importance of activated identity. Annee Psychologique, 103, 411-443.

Reicher, S. (1996). 'The Crowd' century: Reconciling practical success with theoretical failure. British Journal of Social Psychology, 35, 535-553.

Roese, N. J. (1997). Counterfactual thinking. Psychological Bulletin, 121, 133-148.

Silver, L. A., Miller, D. A., Mackie, D. M., \& Smith, E. R. (2001). The nature of intergroup emotions. Unpublished manuscript, University of California, Santa Barbara.

Sloan, L. R. (1989). The motives of sports fans. In J. D. Goldstein (Ed.), Sports, games, and play: Social and psychosocial viewpoints (pp. 175-240). Hillsdale, NJ: Erlbaum.

Smith, E. R. (1993). Social identity and social emotions: Toward new conceptualizations of prejudice. In D. L. Hamilton \& D. M. Mackie (Eds.), Affect, cognition, and stereotyping: Interactive processes in group perception (pp. 297-315). San Diego, CA: Academic Press.

Smith, E. R. (1999). Affective and cognitive implications of a group becoming a part of the self: New models of prejudice and of the selfconcept. In D. Abrams \& M. A. Hogg (Eds.), Social identity and social cognition (pp. 183-196). Malden, MA: Blackwell.

Snyder, C. R., Lassegard, M., \& Ford, C. E. (1986). Distancing after group success and failure: Basking in reflected glory and cutting off reflected failure. Journal of Personality and Social Psychology, 51, 382-388.

Spears, R., Doosje, B., \& Ellemers, N. (1997). Self stereotyping in the face of threats to group status and distinctiveness: The role of group identification. Personality and Social Psychology Bulletin, 23, 538-553.

Spears, R., Doosje, B., \& Ellemers, N. (1999). Commitment and context in the social perception. In N. Ellemers, R. Spears, \& B. Doosje (Eds.), Social identity: context, commitment, content. (pp. 59-83). Oxford, UK: Blackwell. 
Spears, R., Jetten, J., \& Scheepers, D. (2002). Distinctiveness and the definition of collective self: A tripartite model. In A. Tesser, D. A. Stapel, \& J. V. Wood (Eds.), Self and motivation: Emerging psychological perspectives (pp. 147-171). Washington, DC: American Psychological Association.

Steele, C. M., \& Aronson, J. (1995). Stereotype threat and the intellectual test-performance of African-Americans. Journal of Personality and Social Psychology, 69, 797-811.

Stott, C., Hutchison, P., \& Drury, J. (2001).

'Hooligans' abroad? Inter-group dynamics, social identity and participation in collective 'disorder' at the 1998 World Cup Finals. British Journal of Social Psychology, 40, 359-384.

Stott, C. J., \& Adang, O. M. J. (2004, June)

'Disorderly' conduct: Social psychology and the control of football 'hooliganism' at 'Euro2004'. The Psychologist, 318-319.

Stott, C. J., \& Drury, J. (2000). Crowds, context and identity: Dynamic categorization processes in the 'poll tax riot'. Human Relations, 53, 247-273.

Stott, C. J., \& Reicher, S. D. (1998a). How conflict escalates: The inter-group dynamics of collective football crowd 'violence'. Sociology, 32, 353-377.

Stott, C. J., \& Reicher, S. D. (1998b). Crowd action as inter-group process: Introducing the police perspective. European Journal of Social Psychology, 28, 509-529.

Tajfel, H., \& Turner, J. C. (1979). An integrative theory of intergroup conflict. In W. G. Austin \& S. Worchel (Eds.), The social psychology of intergroup relations (pp. 33-48). Monterey, CA: Brooks/Cole.

Tajfel, H., \& Turner, J. C. (1986). The social identity theory of intergroup behavior. In $\mathrm{S}$. Worchel \& W. G. Austin (Eds.), The psychology of intergroup relations (pp. 7-24). Chicago: NelsonHall.

Turner, J. C., Hogg, M. A., Oakes, P. J., Reicher, S. D., \& Wetherell, M. S. (Eds.) (1987). Rediscovering the social group: A self-categorization theory. Oxford, UK: Blackwell.

Wann, D. L., \& Branscombe, N. R. (1990). Die-hard and fair-weather fans: Effects of identification on BIRGing and CORFing tendencies. Journal of Sport and Social Issues, 14, 103-117.

Wann, D. L., Carlson, J. D., \& Schrader, M. P. (1999). The impact of team identification on the hostile and instrumental verbal aggression of sports spectators. Journal of Social Behavior and Personality, 14, 279-286.
Wann, D. L., Dolan, T. J., McGeorge, K. K., \& Allison, J. A. (1994). Relationships between spectator identification and spectators' perceptions of influence, spectators' emotions, and competition outcome. Sport $\mathcal{E}^{\circ}$ Exercise Psychology, 16, 347-364.

Wann, D. L., Hunter, J. L., Ryan, J. A., \& Wright, L. A. (2001). The relationship between team identification and willingness of sports fans to consider illegally assisting their team. Journal of Social Behavior and Personality, 29, 531-536.

Wann, D. L., Peterson, R. R., Cothran, C., \& Dykes, M. (1999). Sport fan aggression and anonymity: The importance of team identification. Journal of Social Behavior and Personality, 27, 597-602.

Yzerbyt, V., Dumont, M., Wigboldus, D., \& Gordijn, E. (2003). I feel for us: The impact of categorization and identification on emotions and action tendencies. British Journal of Social Psychology, 42, 533-549.

Paper received 30 November 2005; revised version accepted 9 May 2006.

\section{Biographical notes}

RICHARD J. CRISP is a reader in social psychology at the University of Birmingham. He did his BA in experimental psychology at the University of Oxford and his PhD at Cardiff University. His research interests focus on social categorization, group processes, and intergroup relations.

SARAH HEUSTON was formerly a student at the University of Birmingham from where she was awarded her BSc in Psychology.

MATTHEW J. FARR is a lecturer in social psychology at Loughborough University. He did his BA in social and political sciences at the University of Cambridge and his PhD at the University of Birmingham. His research interests have focused on prejudice and discrimination, especially social identity approaches to conflict and intergroup relations.

RHIANNON N. TURNER is a postdoctoral research fellow at the University of Birmingham. She did her BSc at Cardiff University, her MSc at the University of Kent, and her D.Phil. at the University of Oxford. Her research interests focus on intergroup relations, specifically on dimensions, mediators and consequences of intergroup contact. 